GAPP, número 24, noviembre de 2020

Sección: RECENSIONES

Recibido: 21-04-2020

Modificado: 03-05-2020

Aceptado: 28-05-2020

DOI: https://doi.org/10.24965/gapp.i24.10794

Páginas: 139-142

\title{
Gómez Puente, Marcos: La Administración electrónica. El procedimiento administrativo digital ${ }^{1}$
}

\section{Gómez Puente, Marcos: La Administración electrónica. El procedimiento administrativo digital}

\author{
Lidia García Martín \\ Universidad de León (España) \\ ORCID: https://orcid.org/0000-0002-5302-6963 \\ lidia.garcia@unileon.es
}

\section{NOTA BIOGRÁFICA}

Contratada FPU. Máster Universitario en Abogacía (2016-2018) y Graduada en Derecho por la Universidad de León (2012-2016). Su principal línea de investigación es la contratación pública electrónica y el procedimiento administrativo telemático.

\section{RESUMEN}

Recensión: Gómez Puente, Marcos: La Administración electrónica. El procedimiento administrativo digital. Thompson Reuters Aranzadi, 1. ${ }^{a}$ ed., 2019, 401 págs.

\section{PALABRAS CLAVE}

Administración electrónica; relación telemática; procedimiento administrativo digital.

\begin{abstract}
Review: Gómez Puente, Marcos: La Administración electrónica. El procedimiento administrativo digital. Thompson Reuters Aranzadi, 1. ${ }^{a}$ ed., 2019, 401 pp.
\end{abstract}

\section{KEYWORDS}

Electronic Administration; telematic relationship; digital administrative procedure.

Ante una situación tan excepcional como la que atraviesa España como consecuencia de la pandemia ocasionada por el COVID-19², el teletrabajo se ha impuesto, en muchos casos, como la medida más adecuada, cuando no única, para hacer frente a dicha situación. Y, al igual ocurre con nuestras Administraciones públicas, dónde el funcionamiento de la Administración electrónica ha sido pieza angular para dar continuidad a la prestación de los servicios públicos.

1 La recensión que ahora se publica está financiada por el Ministerio de Educación, Cultura y Deporte, en el marco de los contratos predoctorales de Formación del Profesorado Universitario (FPU17/00287), así como del proyecto de investigación del Ministerio de Economía y Competitividad DER2017-83864-R, de cuyo equipo de trabajo formo parte.

2 Motivo por el que el estado español decretó el estado de alarma mediante Real Decreto 463/2020, de 14 de marzo, por el que se declaró el estado de alarma para la gestión de la situación de crisis sanitaria ocasionada por el COVID-19. 
En esta línea, el libro del Catedrático de Derecho Administrativo, Gómez Puente "La Administración electrónica. El procedimiento administrativo digital", pretende familiarizar al lector con la configuración de la Administración electrónica. De hecho, son dos las principales aportaciones del libro al presente tema. Por un lado, el imprescindible estudio pasado y presente de las normas sobre el funcionamiento electrónico de la Administración pública, junto con el análisis de las iniciativas nacionales y supranacionales más significativas -que no todas- en el proceso de configuración de la Administración electrónica ${ }^{3}$. Por otro lado, porque al estudio mencionado se une el análisis, también necesario, de los modos, fines y medios técnicos necesarios para su cumplimiento.

Como he tenido oportunidad de anticipar, el punto de partida lo constituyen los principales hitos de la sociedad de la información y la comunicación a los que el autor reserva el capítulo primero. Aunque hubo iniciativas anteriores, con la estrategia de Lisboa se evidenció la necesidad de fomentar el desarrollo de la sociedad de la información. Sin embargo, el grado de cumplimiento de las iniciativas no era homogéneo. Evidentemente, ello no fue obstáculo a su materialización, pero sí supuso un serio retraso en la expansión de los servicios públicos electrónicos. A los planes iniciados a nivel europeo hubo de sumar las iniciativas seguidas en el plano puramente nacional y autonómico. Al igual que ocurrió con las iniciativas europeas, estas fueron de carácter «incompleto, desacompasado e irregular y los resultados previstos no llegaron con la rapidez deseada, ni se materializaron por igual, ni con la integración adecuada».

El análisis del régimen normativo de la Administración electrónica constituye el segundo capítulo del libro. De hecho, la aprobación de la Ley 11/2007, de 22 de junio, de acceso electrónico de los ciudadanos a los servicios públicos ${ }^{4}$, generalizó el uso de las tecnologías de la información y la comunicación ${ }^{5}$ en el funcionamiento de las Administraciones públicas, así como adecuó sus procedimientos, procesos internos y organización a la transformación digital experimentada. De acuerdo con el autor, resultó crucial que las referencias al régimen jurídico de las Administraciones públicas y del procedimiento administrativo común cuando actuasen o se relacionasen por medios electrónicos contenidas en la LAE fuesen consideradas legislación administrativa básica.

Desde la implantación del servicio telegráfico Télex hasta la organización administrativa actual, los cambios han sido significativos. De ahí, que Gómez Puente reserve el capítulo tercero del libro al estudio de la organización administrativa de los servicios públicos telemáticos. Así se forjaron los primeros equipos informáticos y algunos departamentos ministeriales dedicados a la automatización de ciertos procesos. Tras estos, vendrían los negociados, servicios y otras comisiones y juntas de mecanización y automatización, cuya supervisión, apoyo y coordinación se encomendó al Servicio Interministerial de Mecanización ${ }^{6}$, que sería sucedido por la Comisión Interministerial de Informática ${ }^{7}$. Las relaciones de estos órganos con los diferentes departamentos se articularon a través de las comisiones de informática, elementos esenciales en la estructura orgánica y administrativa básica de los departamentos ministeriales.

Hoy en día, la organización administrativa en materia de Administración electrónica pivota en torno a ciertas comisiones dedicadas a las TIC y a la Administración Digital, una secretaria general, un Comité de Dirección y las unidades TIC.

En el cuarto capítulo, el autor se centra en el derecho y las nuevas tecnologías. Ciertamente, la integración y el uso de las herramientas digitales en el procedimiento administrativo supone importantes ventajas para la participación, la eficacia administrativa y la legalidad, siempre que se trabaje en sintonía con el respeto de la seguridad jurídica. Muy acertadamente el autor recuerda que la relación jurídica telemática en nada debe diferenciarse de la efectuada por medios tradicionales. De hecho, el contenido obligacional debe seguir siendo el mismo, solo variando la forma en que se constituyen y ejercen sus derechos. De esta forma, la deslocalización, la modificación de los tiempos y las nuevas formas de la actuación jurídica, dónde se digitalizan las relaciones administrativas, los documentos en los que se instrumentaliza la relación e, incluso,

3 Algunas de las cuestiones sobre las que ya había trabajado con anterioridad, pueden verse en GÓMEZ PUENTE, M. (2011): "El impulso de la sociedad de la información. La Administración electrónica en el marco europeo y estatal”, en PIÑAR MAÑAS, J. L.: Administración electrónica y ciudadanos, págs. 53-114, Navarra: Thomson Reuters, 1. ${ }^{a}$ ed.

4 En adelante, LAE.

5 En adelante, TIC.

6 Dependiente de la Presidencia del Gobierno, de conformidad con el artículo 18 del Decreto 2764/1967, de 27 de noviembre, sobre reorganización de la Administración Civil del Estado para reducir el gasto público.

7 Las actuaciones de la Comisión Interministerial de Informática son respaldadas por el Servicio Central de Informática, dependiente de la Presidencia del Gobierno, en virtud de lo dispuesto en el Decreto 2880/1970, de 12 de septiembre, por el que se crea la Comisión Interministerial de Informática y el Servicio Central de Informática. 
los propios medios a través de los cuales los sujetos se identifican, exteriorizan y confirman su voluntad, constituyen las peculiaridades de la relación jurídica telemática.

El capítulo quinto estudia los sujetos de la relación telemática que la conforman, de un lado, inexcusablemente, una entidad del sector público y, de otro, los particulares, como titulares de los derechos o intereses destinatarios del ejercicio de las potestades administrativas. La relación telemática que institucionalizan las Leyes 39/2015, de 1 de octubre, del Procedimiento Administrativo Común de las Administraciones Públicas ${ }^{8}$ y 40/2015, de 1 de octubre, de Régimen Jurídico del Sector Público ${ }^{9}$, ha traído consigo, a mi juicio, numerosas oportunidades. Ejemplo de ello es la posibilidad de formalizar el apoderamiento mediante el uso de la firma electrónica por comparecencia telemática en la sede electrónica de la Administración. Esta modalidad junto con la creación del «habilitado telemático» al que se encomienda la realización de transacciones electrónicas en representación de los interesados han modificado las formas de representación tradicionales.

El sexto capítulo del libro se destina por el autor al estudio del lugar de la relación administrativa telemática. De esta forma, la sede electrónica se convierte en el lugar a través del cual los particulares interactúan y se relacionan con las Administraciones Públicas.

Ciertamente, la proliferación excesiva de sitios y sedes electrónicas puede dificultar el acceso telemático de los particulares a la información y los servicios públicos. De ahí, la importancia de garantizar un Punto de Acceso General electrónico de la Administración, que permita a los ciudadanos el acceso a toda la información oportuna y a los servicios disponibles en línea de todas las Administraciones públicas. Lo deseable sería, de acuerdo con el autor, alcanzar una concentración y localización de los trámites, servicios e información en un punto de acceso general, la integración de las oficinas de asistencia y el intercambio de información entre Administraciones públicas.

No se descuida, ni mucho menos, el modo y tiempo de la relación administrativa telemática, a los que Gómez Puente reserva el capítulo séptimo. En materia de registros, la voluntad del legislador se orienta a eliminar los registros convencionales, reducir el número de registros electrónicos e integrar en un único sistema todos los sistemas registrales de las Administraciones territoriales y sus organismos y entidades. Sobre el régimen de la notificación administrativa que configura la LPAC, destacan como novedades la indiscutible preferencia de la notificación electrónica frente a la efectuada en papel, el sistema de avisos al interesado de la disponibilidad o envío de una notificación, el Punto de Acceso General en el que estarán accesibles -previsiblemente el 2 abril de $2021^{10}$ - , las notificaciones electrónicas y el establecimiento bien de la sede electrónica bien la dirección electrónica habilitada como los cauces para la práctica de la notificación electrónica. No comparto, como si hace el autor, una posible justificación a la prórroga a la producción de efectos de la hoy -a mi juicio- obligatoria notificación electrónica para los sujetos a los que la LPAC impone la relación telemática ${ }^{11}$.

El octavo capítulo se destina por el autor al estudio del modo en que se producen los actos jurídicos que conforman la relación jurídica, así como el modo en que se deja constancia de estos. Partiendo del principio general de escritura y formalización de los actos administrativos, se permite el uso de documentos electrónicos, siempre que el documento electrónico tenga como rasgo caracterizador la permanencia o inmutabilidad.

El capítulo noveno se centra en el estudio del contenido de la relación telemática. De hecho, la LPAC establece como requisito previo a la elaboración de un proyecto o anteproyecto de ley o de reglamento plan-

En adelante, LPAC.

9 En adelante, LRJSP.

10 Plazo nuevamente ampliado por el Real Decreto-ley 28/2020, de 22 de septiembre, de trabajo a distancia, que modifica la Disposición Final séptima de la LPAC y pospone hasta esa fecha la producción de efectos de las previsiones relativas al registro electrónico de apoderamientos, registro electrónico, registro de empleados públicos habilitados, punto de acceso general electrónico de la Administración y archivo único electrónico. Plazo, que, sin embargo, ya había sido ampliado en dos años por el Real Decreto-ley 11/2018, de 31 de agosto, de transposición de directivas en materia de protección de los compromisos por pensiones con los trabajadores, prevención de blanqueo de capitales y requisitos de entrada y residencia de nacionales países terceros y por el que se modifica la LPAC, al inicialmente previsto por la LPAC que estipulaba el 2 de octubre de 2018 como fecha para la producción de efectos de las medidas de Administración electrónica a las que acabo de referirme.

11 De hecho, aunque se ha diferido en el tiempo la producción de efectos de parte de los aspectos fundamentales de la configuración de la Administración electrónica a los que hace referencia la Disposición final séptima de la LPAC, como son las previsiones relativas al registro electrónico de apoderamientos, registro electrónico, registro de empleados públicos habilitados, punto de acceso general electrónico de la Administración y archivo único electrónico, considero que si el legislador hubiera querido posponer la entrada en vigor de la notificación electrónica obligatoria para los sujetos a los que impone forzosamente la relación telemática en el art. 14.2 de la LPAC, lo hubiera hecho constar, como el resto de supuestos, en la citada disposición final. 
tear una consulta pública, sin perjuicio de que el resto del precepto -a salvo de cierta excepción- haya sido declarado contrario al orden constitucional de competencias e inaplicable a las Comunidades Autónomas ${ }^{12}$. Consulta pública que debe sustanciarse telemáticamente a través de un portal web.

Cierra con el tratamiento de la seguridad de la información y la protección de datos de carácter personal. En efecto, el modelo de Administración electrónica implica serios riesgos para la intimidad y otros derechos y libertades de las personas físicas, de ahí que sea esencial que la actividad telemática de las Administraciones públicas, así como las garantías técnicas para el tratamiento de datos de carácter personal, se asiente indiscutiblemente sobre el respeto y la compatibilidad con la legislación de protección de datos.

Suscribo la máxima de que toda crisis es una oportunidad para aprovechar, hoy más que nunca, los beneficios que reporta el uso de la Administración electrónica. De esta manera, con una sistemática propia de un manual, estructurado en diez capítulos, con un lenguaje claro y sin excesivos formalismos, su lectura servirá como guía de apoyo a todo aquel iniciado -o no tan iniciado- en el estudio de la Administración electrónica, en sus vertientes normativa e informática, que pretenda comprender el por qué, cómo y cuándo de la Administración electrónica.

\section{REFERENCIAS}

GÓMEZ PUENTE, M. (2011): "El impulso de la sociedad de la información. La Administración electrónica en el marco europeo y estatal", en PIÑAR MAÑAS, J. L.: Administración electrónica y ciudadanos, págs. 53-114. Navarra: Thomson Reuters. 1. ${ }^{a}$ ed.

12 STC 55/2018, de 24 de mayo. 